\title{
Knowledge about cataract, glaucoma, and age related macular degeneration in the Hong Kong Chinese population
}

\author{
J T F Lau, V Lee, D Fan, M Lau, J Michon
}

Series editors: W V Good and S Ruit

See end of article for authors' affiliations

......................

Correspondence to: Dr John Michon,

Department of

Ophthalmology, Duke

University School of

Medicine, Durham, NC

27710, USA

micho001@mc.duke.edu

Accepted for publication 3 May 2002

\begin{abstract}
Aims: Patients' knowledge and participation in their care are important in prevention of blindness from common eye diseases such as cataract, glaucoma, and age related macular degeneration (AMD). The aim of this study was to measure knowledge of these conditions in the Hong Kong Chinese population. Methods: Subjects aged 40 and above in the Shatin district of Hong Kong were randomly selected as part of a larger study of causes of adult visual loss. The subjects received eye examinations in which the primary cause of visual disability was recorded. The respondents were asked by trained interviewers in a standardised fashion about their knowledge of cataract, glaucoma, and AMD. Their answers were rated for accuracy by a senior ophthalmologist.

Results: Out of the 2538 eyes examined, $7.0 \%$ had visual acuity less than $6 / 18$. Fully $69.6 \%$ of the visual disability for those aged 60 or above was caused by cataract, AMD, or glaucoma. Awareness of cataract in particular was high, in that over $90 \%$ of respondents had heard of it. However, only $22.9 \%$ of them could describe cataract symptoms correctly, and these percentages were even lower in glaucoma $(10.2 \%)$ and $A M D(<1 \%)$. Over $40 \%$ of subjects did not know that surgery was an appro-
\end{abstract} priate treatment for cataract.

Conclusion: This sample of the Hong Kong Chinese population had limited knowledge of common eye diseases. Educational programmes to enhance public awareness may be needed to improve the effectiveness of health promotion and thus prevent unnecessary blindness.

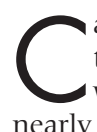
ataract, ${ }^{1-3}$ glaucoma, ${ }^{4}$ and age related macular degeneration (AMD $)^{56}$ are leading causes of blindness worldwide. In a recent study among the Hong Kong Chinese, nearly $80 \%$ of cases of reduced vision (not due to refractive error) were caused by these three eye diseases. ${ }^{7}$ Patients' knowledge is therefore relevant to the prevention of blindness, since both cataract and glaucoma are treatable conditions.

Snellen visual acuity is not the only factor of concern in treatment of cataract. ${ }^{8}$ Surgery is usually indicated only when the cataract causes significant functional disability. This depends on the patient's perception of symptoms, their impact on daily activities and comorbid conditions. In contrast, visual loss from glaucoma is irreversible and is often imperceptible in early stages. Over 60 million individuals worldwide are estimated to have glaucoma; yet, in developed countries only about half of those with glaucoma have been diagnosed. ${ }^{9}$

AMD is another cause of blindness which has become increasingly prevalent. ${ }^{56}$ It is the leading cause of blindness for those age 55 and above in the United States and in some European countries. ${ }^{10}$ With improved diagnosis and treatment of diabetic retinopathy, AMD is becoming more important than diabetes in causing permanent visual loss. Its prevalence in the Chinese population is increasing, particularly with the rapid growth of the elderly population. ${ }^{11}$ Although there is no effective treatment for most cases of AMD, risk factors such as smoking $^{12}$ and low dietary intake of antioxidant vitamins ${ }^{13}$ may be modifiable. In addition, patient knowledge of the nature and prognosis of AMD may prevent them from investing false hopes in potentially dangerous folk remedies.

Individual awareness and knowledge of eye diseases are important factors in screening, diagnosis, treatment compliance, and prevention. This has also been demonstrated in diseases such as hypertension, ${ }^{14}$ cancer, ${ }^{15}$ and alcohol abuse. ${ }^{16}$ However, measurement of the problem on population based samples, especially in ophthalmology, has been limited. In an
Australian study, $74 \%$ of the respondents had accurate knowledge of cataract, but only $19 \%$ and $2 \%$ had accurate knowledge of glaucoma and AMD, respectively. ${ }^{17}$ Therefore, there may be a lack of correct knowledge of common eye diseases even in developed countries. The aim of this study was to assess the knowledge of cataract, glaucoma, and AMD in the Hong Kong Chinese. To our knowledge, this is the first study to measure the understanding of common eye diseases in a Chinese population.

\section{SUBJECTS AND METHODS}

\section{Study population and sampling}

The study population consisted of Chinese people aged 40 or above who had been living in the Shatin District of Hong Kong for at least 6 months. Shatin is a densely populated suburban town in the New Territories area of Hong Kong, comprising $69.4 \mathrm{~km}^{2}$ in area with a population of about 583000 . It is comparable with the entire Hong Kong territory with respect to age and household income. ${ }^{7}$

A random sample of addresses was provided by the Census and Statistics Department of the Government of Hong Kong. The sample was stratified into three age groups (40-50, 50-65, and $65+$ ) in the rough ratios of 1:2:2 (the actual sample sizes obtained were 269,568 , and 433 respectively). The selected households were visited by trained interviewers within 1 week after sending out the letter of introduction. A reminder letter was left behind if no contact was made to remind the household of a future visit. Attempts to revisit refused households were also made after a follow up letter was sent to the household. A household was defined as a "no contact" one if nobody answered the door after five approaches were made on separate days, and was defined as "vacant" after being confirmed by the neighbours. After a contact had been made, the interviewer enumerated the number of eligible people 
Table 1 Self reported prevalence of glaucoma, cataract, and AMD by sex and age

\begin{tabular}{|c|c|c|c|c|c|c|c|}
\hline & \multicolumn{2}{|l|}{ Sex } & \multicolumn{3}{|l|}{ Age } & \multirow{2}{*}{$\begin{array}{l}\text { Total } \\
\text { (unadjusted) }\end{array}$} & \multirow[b]{2}{*}{ Total (adjusted)* } \\
\hline & Male & Female & $40-59$ & $60-69$ & $70+$ & & \\
\hline & No (\%) & No (\%) & No (\%) & No (\%) & No $(\%)$ & No & No (\%) \\
\hline \multicolumn{8}{|l|}{ Glaucoma } \\
\hline Yes & $9(1.6)$ & $10(1.5)$ & $5(0.7)$ & $4(1.1)$ & $10(4.1)$ & $19(1.5)$ & $1.5 \%$ \\
\hline No & $571(98.4)$ & $679(98.5)$ & $666(99.3)$ & 349 (98.9) & 235 (95.9) & 1250 (98.5) & $98.5 \%$ \\
\hline $95 \% \mathrm{Cl}$ & 0.8 to 3.0 & 0.6 to 2.3 & 0.3 to 1.8 & 0.4 to 3.1 & 1.6 to 6.6 & 0.8 to 2.2 & 0.7 to 2.3 \\
\hline \multicolumn{8}{|l|}{ Cataract } \\
\hline Yes & $52(9.0)$ & $129(18.7)$ & $21(3.1)$ & $58(16.4)$ & $102(41.6)$ & $181(14.3)$ & $9.7 \%$ \\
\hline No & 528 (91.0) & $560(81.3)$ & $650(96.9)$ & $295(83.6)$ & $143(58.4)$ & 1088 (85.7) & $90.3 \%$ \\
\hline $95 \% \mathrm{Cl}$ & 0.8 to 3.0 & 0.6 to 2.3 & 1.8 to 4.4 & 12.6 to 20.3 & 35.5 to 47.8 & 12.3 to 16.2 & 8.4 to 10.9 \\
\hline \multicolumn{8}{|l|}{$A M D$} \\
\hline Yes & $1(0.2)$ & $3(0.4)$ & $2(0.3)$ & $1(0.3)$ & $1(0.4)$ & $4(0.3)$ & $0.4 \%$ \\
\hline No & $579(99.8)$ & $686(99.6)$ & $669(99.7)$ & 352 (99.7) & $244(99.6)$ & 1265 (99.7) & $99.6 \%$ \\
\hline $95 \% \mathrm{Cl}$ & 0.8 to 3.0 & 0.6 to 2.3 & 0.1 to 1.2 & 0.0 to 1.8 & 0.0 to 2.6 & 0.1 to 0.9 & 0.0 to 0.8 \\
\hline
\end{tabular}

within the household. When there was more than one eligible person, one of them was selected randomly by the Kish table method and invited to join the study. A total of $83.8 \%$ of the households contacted had at least one eligible person.

A structured questionnaire was administered to collect data on demographics (including education and income) and knowledge on particular eye diseases. An appointment was then made with the subject for a free eye examination at the eye clinic of the Prince of Wales Hospital. A travel allowance $(\mathrm{HK} \$ 60)$ was offered to those subjects with mobility problems. Home visits by the study ophthalmologist was also offered to senior subjects or those having severe mobility problems. A total of 1269 adults completed the questionnaires and the eye examination.

\section{Eye examination at the test site}

In this study, a person is defined as having visual disability if either of their eyes has a pinhole visual acuity of less than 6/18. This corresponds to the World Health Organization definition of visual disability. Written informed consent was obtained. The subjects underwent a general eye examination including distance and near visual acuity, lensometry and autorefraction, measurement of intraocular pressure, and funduscopy. Acuity was measured with the subjects' normal distance correction worn and the pinhole device was used to minimise any residual refractive error if the non-pinhole acuity was less than or equal to 6/18. The subjects' eyes were dilated and the anterior and posterior segments of the eye were examined. The examinations were performed by trained optometrists and a study ophthalmologist. The cause of visual disability was recorded. When more than one cause was present, the cause judged to be of greatest impact was assigned as the primary cause. The respondents were then interviewed by research staff in a standardised manner using a structured questionnaire. All interviews were in Cantonese, the local Chinese dialect of Hong Kong.

\section{Coding end points}

Respondents were asked whether they were aware of cataract, glaucoma, and AMD. They were also asked to describe the symptoms of these conditions, how they affected the eye and to name their appropriate treatments. The results given by all the respondents were coded into three categories by one of the authors who is a senior ophthalmologist (VL). The three categories were (1) whether the respondents had given any reply describing the disease, (2) whether they were describing the symptoms correctly, and (3) whether they were describing the pathophysiology (physiology or anatomy or both) correctly. A subsample of the answers $(n=100)$ was coded by another ophthalmologist (DF). The kappa values were calculated to determine the agreement between the coding by the two ophthalmologists. For the aspect of symptoms, the kappa values were $0.613,0.844$, and 0.707 for glaucoma, cataract, and AMD respectively. For the pathophysiology aspect, kappa values ranged between $0.578,0.578$, and 0.834 for these three diseases respectively. These ranges are consistent with those recently reported (kappa values from 0.55-0.83) for board certified ophthalmologists in the United States asked to evaluate standards of clinical care. ${ }^{18}$

\section{Statistical methods}

$\chi^{2}$ Analysis was used to test the statistical significance of various factors on the knowledge of eye diseases univariately, and odds ratios were calculated. Logistic regression models were used to examine the effects of various factors on the knowledge of eye diseases. spss statistical software version 9.0 was used for data analyses.

\section{RESULTS}

Measurement of cataract, glaucoma, and AMD as the primary cause of visual disability

Of the 2538 eyes examined, $7.0 \%(178 / 2,538)$ had pinhole visual acuity less than $6 / 18$. They were distributed as follows: $1.8 \%(24 / 1342)$ of eyes less than $6 / 18$ for the $40-59$ age group, $6.2 \%(44 / 706)$ for the $60-69$ age group, and $22.4 \%$ (110/490) for the 70 or above age group, respectively. The primary cause of visual loss could be determined in 170 of these 178 eyes. Cataract accounted for $50.6 \%$ of the visual impairment $(4.5 \%$, $39.5 \%$, and $64.8 \%$ respectively for the three above mentioned age groups). AMD was responsible for $7.1 \%$ (0\%, 7\%, and 8.6\% respectively for the three age groups), and glaucoma accounted for $4.1 \%(4.5 \%, 0 \%$, and $5.7 \%$ respectively for the three age groups). These three conditions together accounted for $69.6 \%(103 / 148)$ of all visual loss for the age group 60 or above.

\section{Self reported prevalence for cataract, glaucoma, and AMD}

Self reported prevalence data for cataract, glaucoma, and AMD are presented in Table 1. Female subjects were significantly more likely than males to have a self reported diagnosis of cataract $(\mathrm{OR}=1.72, \mathrm{p}<0.05)$. There were no sex differences for the self reported prevalence of AMD and glaucoma $(p=0.630$ and $p=0.883$ respectively). Older age groups were significantly more likely to have self reported cases of cataract or glaucoma $\left(\chi^{2}\right.$ for trend $=212.43, \mathrm{p}<0.001$ and 11.35, $\mathrm{p}<0.001$, respectively; Table 1). Insufficient data were present to analyse self reporting of AMD.

Among those who had at least one eye with visual loss attributed to cataract, AMD, or glaucoma $(n=105), 46.5 \%$, 
Table 2 Knowledge of symptoms and pathophysiology of cataract, AMD, and glaucoma

\begin{tabular}{|c|c|c|c|c|c|c|c|}
\hline & $\begin{array}{l}\text { Never heard of } \\
\text { the disease }\end{array}$ & $\begin{array}{l}\text { Heard of the } \\
\text { disease, but could } \\
\text { not describe it at all }\end{array}$ & $\begin{array}{l}\text { Symptoms } \\
\text { described } \\
\text { incorrectly }\end{array}$ & $\begin{array}{l}\text { Symptoms } \\
\text { described } \\
\text { correctly }\end{array}$ & & & All \\
\hline \multicolumn{8}{|c|}{ Knowledge of symptoms } \\
\hline Cataract & $90(7.1 \%)$ & $837(66.0 \%)$ & $50(3.9 \%)$ & $291(22.9 \%)$ & & & $\begin{array}{l}1268 \\
(100 \%)\end{array}$ \\
\hline$A M D$ & $1151(90.8 \%)$ & $107(8.4 \%)$ & $5(0.4 \%)$ & $5(0.4 \%)$ & & & $\begin{array}{l}1268 \\
(100 \%)\end{array}$ \\
\hline \multirow[t]{2}{*}{ Glaucoma } & $274(21.6 \%)$ & $535(42.2 \%)$ & $330(26.0 \%)$ & $129(10.2 \%)$ & & & $\begin{array}{l}1268 \\
(100 \%)\end{array}$ \\
\hline & $\begin{array}{l}\text { Never heard of } \\
\text { the disease }\end{array}$ & $\begin{array}{l}\text { Heard of the } \\
\text { disease, but could } \\
\text { not describe it at all }\end{array}$ & $\begin{array}{l}\text { Physiology } \\
\text { described } \\
\text { correctly }\end{array}$ & $\begin{array}{l}\text { Anatomy } \\
\text { described } \\
\text { correctly }\end{array}$ & $\begin{array}{l}\text { Both described } \\
\text { incorrectly }\end{array}$ & $\begin{array}{l}\text { Both described } \\
\text { correctly }\end{array}$ & All \\
\hline \multicolumn{8}{|c|}{ Knowledge of pathophysiology } \\
\hline Cataract & $90(7.1 \%)$ & $568(44.8 \%)$ & $142(11.2 \%)$ & $48(3.8 \%)$ & $391(30.8 \%)$ & $29(2.3 \%)$ & $\begin{array}{l}1268 \\
(100 \%)\end{array}$ \\
\hline$A M D$ & $1151(90.8 \%)$ & $89(7.0 \%)$ & $2(0.2 \%)$ & $1(0.1 \%)$ & $23(1.8 \%)$ & $2(0.2 \%)$ & $\begin{array}{l}1268 \\
(100 \%)\end{array}$ \\
\hline Glaucoma & $274(21.6 \%)$ & 875 (69.0\%) & $3(0.2 \%)$ & $11(0.9 \%)$ & $76(6.0 \%)$ & $29(2.3 \%)$ & $\begin{array}{l}1268 \\
(100 \%)\end{array}$ \\
\hline
\end{tabular}

$8.3 \%$, and $100 \%$ respectively had been diagnosed by a doctor as having these eye conditions before this study (data not shown). With respect to family history, $23.5 \%, 0.1 \%$, and $3.7 \%$ respectively reported that one or more of their first or second degree family members (grandparents, parents, siblings, or children) had been diagnosed with cataract, AMD, or glaucoma respectively (data not shown).

\section{Knowledge about symptoms, pathophysiology, and treatment of cataract}

Although nearly all of the respondents $(92.9 \%)$ stated that they had heard of cataract, only $22.9 \%$ described its symptoms correctly $(66.0 \%$ could not describe them at all and $3.9 \%$ described them incorrectly (see Table 2 )). Only $2.3 \%$ of the respondents described both the physiology and anatomy correctly, while $11.2 \%$ described the physiology correctly but described the anatomy incorrectly; and 3.8\% described the anatomy correctly but the physiology incorrectly (Table 2). Both aspects were described incorrectly by $30.8 \%$ (390/1268).

Surgery as a treatment for cataract was mentioned by $57.6 \%$ (730/1268) of all respondents while 5.5\% (70/1268) mentioned at least one inappropriate treatment for cataract (such as wearing glasses, drugs, laser treatment, vitamin supplement, nutrition treatments, and Chinese herbal remedies (see Table 3$)$ ). The three most frequently mentioned inappropriate treatments were laser treatment $(3.5 \%)$, drugs $(1.2 \%)$, and wearing glasses $(0.6 \%)$ (see Table 3 ).

While sex was not a factor predicting whether the respondents had heard of cataract, younger, better educated and higher income groups were more likely to have heard of the condition than older, less educated, or lower income respondents (Table 4). Similarly, younger, male, better educated, and higher income groups were more likely to describe either the anatomy or physiology of cataract correctly than other respondents (Table 4). With regard to the correct description of symptoms, education was the only statistically significant predictor $(\mathrm{p}=0.001$, see Table 4$)$.

\section{Knowledge about symptoms, pathophysiology, and treatment of glaucoma}

Nearly eight of 10 of the respondents $(78.4 \%)$ were aware of glaucoma, but only $10.2 \%$ could describe its symptoms correctly; $42.2 \%$ said that they had heard of the disease but could not describe its symptoms (or lack thereof) at all; the other $26.0 \%$ described the symptoms incorrectly (Table 2 ). Only $1.1 \%$ of the respondents described either the anatomy or physiology of glaucoma correctly and only $2.3 \%$ described both correctly.

\begin{tabular}{|c|c|}
\hline & Cataract $(n=1268)$ \\
\hline Knowledge of treatments $\dagger$ & No (\%) \\
\hline $\begin{array}{l}\text { Wearing spectacles } \\
\text { Surgery* } \\
\text { Drugs } \\
\text { Laser treatment } \\
\text { Vitamin supplement } \\
\text { Nutrition treatment } \\
\text { Visiting ophthalmologist } \\
\text { Chinese herbal medicine } \\
\text { Don't know } \\
\text { Others }\end{array}$ & $\begin{array}{l}8(0.6) \\
730(57.6) \\
15(1.2) \\
44(3.5) \\
1(0.1) \\
1(0.1) \\
36(2.8) \\
2(0.2) \\
376(29.7) \\
33(2.6)\end{array}$ \\
\hline Others & $\begin{array}{l}\text { Glaucoma }(n=1268) \\
\text { No }(\%)\end{array}$ \\
\hline $\begin{array}{l}\text { Wearing glasses } \\
\text { Surgery* } \\
\text { Drugs* } \\
\text { Laser treatment* } \\
\text { Vitamin supplement } \\
\text { Nutrition treatment } \\
\text { Visiting ophthalmologist } \\
\text { Chinese herbal medicine } \\
\text { Don't know } \\
\text { Others }\end{array}$ & $\begin{array}{l}5(0.4) \\
75(5.9) \\
20(1.6) \\
26(2.1) \\
2(0.2) \\
0(0.0) \\
45(3.5) \\
2(0.2) \\
777(61.3) \\
60(4.7)\end{array}$ \\
\hline & $\begin{array}{l}\text { AMD }(n=1268) \\
\text { No (\%) }\end{array}$ \\
\hline $\begin{array}{l}\text { Wearing glasses } \\
\text { Surgery* } \\
\text { Drugs } \\
\text { Laser treatment* } \\
\text { Vitamin supplement* } \\
\text { Nutrition treatment } \\
\text { Visiting ophthalmologist } \\
\text { Chinese herbal medicine } \\
\text { Don't know } \\
\text { Others }\end{array}$ & $\begin{array}{l}0(0.0) \\
5(0.4) \\
4(0.3) \\
1(0.1) \\
1(0.1) \\
1(0.1) \\
3(0.2) \\
0(0.0) \\
82(6.5) \\
6(0.5)\end{array}$ \\
\hline
\end{tabular}

Male, younger, better educated, and higher income groups were more likely to have heard of the disease than other respondents. However, sex (but not age, education, or income) was the only significant predictor of knowledge about 
Table 4 Factors associated with knowledge of eye diseases

\begin{tabular}{|c|c|c|c|c|c|c|}
\hline & \multicolumn{2}{|l|}{ Cataract $(n=1268)$} & \multicolumn{2}{|l|}{ Glaucoma (n=1268) } & \multicolumn{2}{|l|}{$\operatorname{AMD}(n=1268)$} \\
\hline & Odds ratio $(95 \% \mathrm{Cl})$ & $\mathrm{p}$ Value & Odds ratio $(95 \% \mathrm{Cl})$ & $\mathrm{p}$ Value & Odds ratio $(95 \% \mathrm{Cl})$ & $\mathrm{p}$ Value \\
\hline \multicolumn{7}{|l|}{ Heard about the disease } \\
\hline Age: & & 0.001 & & $<0.001$ & & 0.089 \\
\hline $40-49$ (ref) & 1.00 & - & 1.00 & - & 1.00 & - \\
\hline $50-59$ & $0.46(0.21$ to 1.04$)$ & 0.062 & $0.52(0.32$ to 0.85$)$ & 0.009 & $0.77(0.47$ to 1.26$)$ & 0.294 \\
\hline $60-69$ & $0.37(0.17$ to 0.83$)$ & 0.016 & $0.33(0.21$ to 0.54$)$ & $<0.001$ & $0.69(0.41$ to 1.16$)$ & 0.158 \\
\hline 70 or above & $0.22(0.10$ to 0.49$)$ & $<0.001$ & 0.15 (0.09 to 0.24$)$ & $<0.001$ & $0.44(0.23$ to 0.84$)$ & 0.012 \\
\hline \multicolumn{7}{|l|}{ Sex: } \\
\hline Male (ref) & 1.00 & - & 1.00 & - & 1.00 & - \\
\hline Female & $0.82(0.53$ to 1.26$)$ & 0.362 & $0.67(0.51$ to 0.88$)$ & 0.004 & 1.39 (0.94 to 2.05$)$ & 0.098 \\
\hline Education: & & $<0.001$ & & $<0.001$ & & 0.036 \\
\hline None (ref) & 1.00 & - & 1.00 & - & 1.00 & - \\
\hline Primary & 1.90 (1.17 to 2.94$)$ & 0.009 & 2.31 (1.69 to 3.17 ) & $<0.001$ & $0.97(0.56$ to 1.68$)$ & 0.910 \\
\hline Secondary or above & 9.80 (4.53 to 21.22$)$ & $<0.001$ & $6.99(4.73$ to 10.3$)$ & $<0.001$ & $1.62(0.97$ to 2.72$)$ & 0.066 \\
\hline Household income: & & 0.004 & & $<0.001$ & & 0.047 \\
\hline$\$ 0-10000$ (ref) & 1.00 & - & 1.00 & - & 1.00 & - \\
\hline$\$ 10001-25000$ & 1.94 (1.02 to 3.67$)$ & 0.042 & 1.98 (1.31 to 3.00$)$ & 0.001 & $1.61(0.82$ to 3.17$)$ & 0.169 \\
\hline$\$ 25000+$ & 4.61 (1.82 to 11.72$)$ & 0.001 & 2.89 (1.76 to 4.76$)$ & $<0.001$ & 2.33 (1.17 to 4.65$)$ & 0.016 \\
\hline \multicolumn{7}{|c|}{ Described symptoms correctly } \\
\hline Age: & & 0.264 & & 0.187 & NA & NA \\
\hline $40-49$ (ref) & 1.00 & - & 1.00 & - & & \\
\hline $50-59$ & 0.84 (0.59 to 1.19$)$ & 0.320 & 1.09 (0.65 to 1.83 ) & 0.742 & & \\
\hline $60-69$ & $0.76(0.53$ to 1.10$)$ & 0.152 & 1.33 (0.80 to 2.22$)$ & 0.275 & & \\
\hline 70 or above & 0.67 (0.44 to 1.02$)$ & 0.059 & 0.70 (0.37 to 1.32$)$ & 0.273 & & \\
\hline \multicolumn{7}{|l|}{ Sex: } \\
\hline Male (ref) & 1.00 & - & 1.00 & - & & \\
\hline Female & $1.12(0.86$ to 1.45$)$ & 0.413 & 1.65 (1.13 to 2.42 ) & 0.009 & NA & NA \\
\hline Education: & & 0.001 & & 0.482 & NA & NA \\
\hline None (ref) & 1.00 & - & 1.00 & - & & \\
\hline Primary & $1.60(1.10$ to 2.35$)$ & 0.016 & 1.28 (0.77 to 2.13$)$ & 0.339 & & \\
\hline Secondary or above & 2.02 (1.39 to 2.94 ) & $<0.001$ & $1.36(0.82$ to 2.26$)$ & 0.234 & & \\
\hline Household income: & & 0.501 & & 0.607 & NA & NA \\
\hline$\$ 0-10000$ (ref) & 1.00 & - & 1.00 & - & & \\
\hline$\$ 10001-25000$ & 0.98 (0.65 to 1.49 ) & 0.937 & 1.15 (0.67 to 1.99 ) & 0.615 & & \\
\hline$\$ 25000+$ & $1.22(0.78$ to 1.88$)$ & 0.384 & 0.89 (0.48 to 1.64$)$ & 0.701 & & \\
\hline \multicolumn{7}{|c|}{ Described pathophysiology correctly (either physiology or anatomy described correctly) } \\
\hline Age: & & $<0.001$ & & 0.003 & & \\
\hline $40-49$ (ref) & 1.00 & - & 1.00 & - & & \\
\hline $50-59$ & $0.60(0.42$ to 0.87$)$ & 0.006 & $0.69(0.35$ to 1.37$)$ & 0.295 & & \\
\hline $60-69$ & $0.32(0.21$ to 0.50$)$ & $<0.001$ & $0.17(0.07$ to 0.51$)$ & 0.002 & & \\
\hline 70 or above & $0.30(0.19$ to 0.49$)$ & $<0.001$ & $0.25(0.08$ to 0.74$)$ & 0.013 & & \\
\hline \multicolumn{7}{|l|}{ Sex: } \\
\hline Male (ref) & 1.00 & - & 1.00 & - & & \\
\hline Female & $0.70(0.53$ to 0.94$)$ & 0.019 & $0.80(0.43$ to 1.47$)$ & 0.469 & & \\
\hline Education: & & $<0.001$ & & $<0.001$ & & \\
\hline None (ref) & 1.00 & - & 1.00 & - & & \\
\hline Primary & $2.18(1.31$ to 3.63$)$ & 0.003 & $6.47(0.83$ to 50.4$)$ & 0.075 & & \\
\hline Secondary or above & $4.46(2.74$ to 7.27$)$ & $<0.001$ & 19.7 (2.68 to 145.3$)$ & 0.003 & & \\
\hline Household income: & & 0.002 & & 0.103 & & \\
\hline$\$ 0-10000$ (ref) & 1.00 & - & 1.00 & - & & \\
\hline$\$ 10001-25000$ & 1.92 (1.17 to 3.14 ) & 0.009 & $2.25(0.74$ to 6.78$)$ & 0.149 & & \\
\hline$\$ 25000+$ & $2.52(1.51$ to 4.20$)$ & $<0.001$ & 3.28 (1.08 to 9.97$)$ & 0.036 & & \\
\hline
\end{tabular}

glaucoma symptoms (see Table 4). Factors affecting knowledge of pathophysiology include younger age and higher education levels ( $\mathrm{p}=0.003$ and $\mathrm{p}<0.001$ respectively).

There were $5.9 \%(75 / 1268)$ of the respondents who mentioned surgery as a form of treatment for glaucoma; $2.1 \%$ (26/1268) mentioned laser treatment; $1.6 \%$ (20/1268) mentioned drug treatment, and $0.7 \%(9 / 1268)$ mentioned at least one inappropriate treatment (such as wearing glasses, vitamin supplement, nutrition treatment, and Chinese herbal remedies).

\section{Knowledge about symptoms, pathophysiology, and treatment of AMD}

Only 9.2\% of all respondents had heard of AMD (Table 2). Those with better education or higher income were more likely to have heard of AMD than those with lower education or income (Table 4). Less than $1 \%$ could describe the anatomy or physiology correctly (Table 2). Among the 117 who had heard of AMD, five mentioned "surgery," one mentioned "laser treatment," and one mentioned "vitamin supplementation" as an appropriate treatment (see Table 3). Because of small numbers, factors predicting knowledge about AMD pathophysiology and symptoms were not analysed.

\section{DISCUSSION}

Cataract, glaucoma and AMD accounted for $61.8 \%$ of eyes with visual disability in adults 40 years or above and $69.6 \%$ of eyes with visual disability in those 60 or above in our Hong Kong population. Despite their importance and association with visual disability and blindness, the levels of knowledge concerning these three conditions are quite low. Our Hong Kong adults were more aware of cataract (92.9\%) and 
glaucoma (78.4\%) than AMD (9.2\%). These findings are comparable to a similar study in Australia, ${ }^{17}$ in which respondents were also more aware of cataract (92\%) and glaucoma (79\%) then AMD (5\%). The Australian study reported that 74\%, 19\%, and $2 \%$ of the respondents had correct knowledge of the physiology of cataract, glaucoma, and AMD respectively. Our Hong Kong adults had correct knowledge in $22.9 \%, 10.2 \%$, and less than $1 \%$ of cases, respectively. The definitions used in this study were somewhat different from the Australian study ${ }^{17}$; however, making direct comparison difficult. For example, the Australian study did not report the percentage of subjects with knowledge about correct treatments. Populations in both countries, however, had serious deficiencies in their knowledge, which was also seen in studies from Greece ${ }^{19}$ and southern India. ${ }^{20}$

It is possible that our results may be skewed because subjects with either an existing ocular disorder or interest in ocular disorders would be more likely to participate than those without. However, the relatively low level of visual disability (only $7.0 \%$ of eyes had pinhole acuity less than $6 / 18$ ) suggests that any bias would be very small. Likewise, the general lack of knowledge of eye disorders in our population argues against the idea that those with a special interest in this area would be over-represented.

Early detection and treatment is vital in glaucoma. Given the fact that only $10 \%$ of our subjects knew about its symptoms (or lack thereof in early stages), and that small percentages knew about its anatomy, physiology, or surgery/ laser treatment options, it is unlikely that many patients would come forward for examination. Rather, more intensive education, screening, and community outreach are required to reduce the burden of blindness from glaucoma. Similarly, although AMD is a substantial cause of visual disability for the age group 60 or above, nearly $90 \%$ were unaware of the condition and less than $1 \%$ could describe its symptoms or pathophysiology correctly.

Hong Kong provides many advanced medical services and enjoys one of the longest life expectancies in the world (male $=77.0$ years, female $=82.2$ years, 2000 data). However, knowledge of the major eye diseases is at variance with improvements in safety and effectiveness of ophthalmic therapies. Although most subjects claimed to be aware of cataract or glaucoma, only a minority understood their symptoms, anatomy, or physiology (Table 2). It is also important to note that over $40 \%$ of our sample did not know that surgery is the appropriate treatment for cataract. The implication is that many cataract patients would not seek and utilise proper treatments at an early stage of their eye disease, even in a system that provides nearly universal health coverage. This is consistent with the finding that cataract is the major cause of blindness in the Hong Kong elderly, ${ }^{7}$ even with wide access to ophthalmic services. It further suggests that many cases of visual impairment could have been avoided, provided that patients are educated to a higher level of awareness.

Although much of the registered blindness in developed countries is potentially avoidable, our population is largely ignorant about common eye conditions such as cataract, glaucoma, and AMD. Educational programmes to enhance public awareness of these diseases may improve the effectiveness of health promotion and thus prevent unnecessary blindness in Hong Kong.

\section{ACKNOWLEDGEMENTS}

This project was funded by the Hong Kong Hospital Service Research Fund. The authors would like to thank Edmond Ng for organising the field work.

Financial and proprietary interest: Nil.

Financial support: Supported by the Hong Kong Hospital Service Research Fund.

\section{Authors' affiliations}

J T F Lau, Centre for Clinical Trials and Epidemiological Research, Chinese University of Hong Kong

V Lee, Department of Surgery and Anatomy, Hong Kong University and Hong Kong Adventist Hospital Eye Centre

D Fan, Departemnt of Ophthalmology and Visual Sciences, Chinese University of Hong Kong

M Lau, Centre for Clinical Trials and Epidemiological Research, Chinese University of Hong Kong

J Michon, Department of Ophthalmology, Duke University School of Medicine, Durham, NC, USA

\section{REFERENCES}

1 Mitchell $\mathbf{P}$, Cumming RG, Attebo K, et al. Prevalence of cataract in Australia: the Blue Mountains eye study. Ophthalmology 1997; 104:581-8.

2 Leske MC, Connel AM, Wu SY, et al. Prevalence of lens opacities in the Barbados Eye Study. Arch Ophthalmol 1997;115:105-11.

3 Klein BE, Klein R, Linton KL. Prevalence of age-related lens opacities in a population. The Beaver Eye Study. Ophthalmology 1992; 99:546-52.

4 Coleman AL. Glaucoma. Lancet 1999;354:1803-10.

5 Fine SL, Berger JW, Maguire MG, et al. Age-related macular degeneration. N Engl J Med 2000;342:483-92.

6 Klein R, Klein BEK, Linton KLP. Prevalence of age-related maculopathy: the Beaver Dam Eye Study. Ophthalmology 1992;99:933-45.

7 Lau JTF, Michon JM, Chan WS, et al. Prevalence of visual impairment, blindness, and cataract surgery in Hong Kong elderly. Br J Ophthalmol 2002;86:12-7.

8 Royal Australian College of Ophthalmologists. Preferred practice patterns. Cataract and intraocular lens surgery in the otherwise health adult eye. Sydney: Royal Australian College of Ophthalmologists, 1995

9 Quigley HA. Number of people with glaucoma worldwide. Number of people with glaucoma worldwide. BrJ Ophthalmol 1996;80:389-93.

10 Evans J, Wormald R. Is the incidence of registrable age-related macular degeneration increasing? Br J Ophthalmol 1996;80:9-14.

11 Lim JI, Lwok A, Wilson DK. Symptomatic age-related macular degeneration in Asian patients. Retina 1998;18:435-8.

12 Seddon JM, Willett WC, Speizer FE, et al. A prospective study of cigarette smoking and age-related macular degeneration in women. JAMA 1996;276:1141-6.

13 The Eye Disease Case-Control Study Group. Risk factors for neovascular age-related macular degeneration. Arch Ophthalmol 1992;110:1701-8.

14 Garraway WM, Whisnant. The changing pattern of hypertension and the declining incidence of stroke. JAMA 1987;258:214-7.

15 Woerden JK, Solomon LS, Flynn BS, et al. A community wide program in breast self-examination training and maintenance. Prev Med 1990; 19:254-69.

16 Kraft DP. The prevention and treatment of alcohol problems on college campus. J Alcohol Drug Ed 1988;34:37-51

17 Livingston PM, McCarty CA, Taylor HR. Knowledge, attitudes, and self care practices associated with age related eye disease in Australia. $\mathrm{Br} J$ Ophthalmol 1998;82:780-5.

18 Margo CE. Peer and expert opinion and the reliability of implicit case review. Ophthalmology 2002;109:614-8.

19 Konstas AG, Maskaleris G, Gratsonidis S, et al. Compliance and viewpoint of glaucoma patients in Greece. Eye 2000;14 Pt 5:752-6.

20 Dandona R, Dandona L, John RK, et al. Awareness of eye diseases in an urban population in southern India. Bull World Health Organ $2001 ; 79: 96-102$. 